\title{
Interspecific Crossability of Selected Salvia Species and Potential Use for Crop Improvement
}

\author{
Joseph Tychonievich and Ryan M. Warner' \\ Department of Horticulture, Michigan State University, A234 Plant and Soil Sciences Building, East \\ Lansing, MI 48824
}

\begin{abstract}
AdDITIONAL INDEX words. hybridization, Lamiaceae, chromosome number, phylogeny
Abstract. The wide diversity in the genus Salvia represents an untapped genetic resource to improve and diversify Salvia grown as floriculture crops. Interspecific hybrids have formed naturally or by chance hybridization of cultivated plants, but the degree to which species are cross-compatible is largely unknown. The crossability of nine Salvia species selected to cover a wide range of the diversity in European and American species was evaluated in a full diallel mating scheme. Overall, crossability of the selected species was low with only five of 72 interspecific cross combinations producing viable seed, whereas all nine species were self-fertile. Successful crosses were mostly within close phylogenetic groupings. The majority of successful crosses were between species with different chromosome numbers, suggesting that chromosome number differences alone are not a major barrier to hybridization in this genus. A Salvia nemorosa $\times$ Salvia transslyvanica $\mathbf{F}_{2}$ population exhibited transgressive segregation for several horticulturally important traits, including flower size, plant height, and time to flower. Plant height was correlated positively with flower length, inflorescence branch number, and time to flower. Time to flower was correlated positively with flower length. Individuals with desirable trait combinations were identified within the population.
\end{abstract}

With 900 species, native to every continent except Antarctica and Australia (Mabberly, 2008) and possessing a myriad of growth habits and flower colors, the genus Salvia represents an extraordinary range of diversity. Several species are widely used as ornamental plants. Salvia splendens and S. farinacea are widely grown seed-propagated annual bedding plants, whereas $S$. nemorosa is a popular herbaceous perennial species with both seed and vegetatively propagated cultivars. Although these and other species of Salvia are widely used horticulture crops, the diversity of the genus represents a largely untapped resource for crop improvement, which might be accessed by means of interspecific hybridization. There are a number of known interspecific hybrids in the genus. However, with the exception of intentional crosses between culinary sage $(S$. officinalis) and S. lavandulifolia (Sanchez-Gomez et al., 1995), S. fruticosa, and S. tomentosa (Putievsky et al., 1990), all reported hybrids have occurred spontaneously either in the wild or in cultivation. There is a paucity of information concerning the interspecific fertility of Salvia species.

The crossability of two species is often related to phylogenetic relationship and chromosome number. Crosses between closely related species with the same chromosome number are more likely to hybridize and produce fertile progeny, whereas crosses between distantly related species with different chromosome numbers are more likely to either not hybridize or to produce sterile offspring resulting from genetic incongruity or meiotic errors (Harlan and DeWet, 1971; Sybenga, 1992).

The phylogenetic grouping of species into the genus Salvia was based on a key morphological feature, namely the elongated connective between the two thecae of the anthers (ClaßenBockhoff et al., 2003). The validity of this grouping was called into question by Walker et al. (2004), who constructed a phylogeny based on $r b c L$ and $\operatorname{trn} L-F$ gene sequences from 127 Salvia taxa. Based on these data, they concluded that Salvia is

Received for publication 28 July 2010. Accepted for publication 20 Oct. 2010. ${ }^{1}$ Corresponding author. E-mail: warnerry@msu.edu. not monophyletic, but rather composed of three separate monophyletic clades. Although the polyphyletic nature of the genus was unexpected, the clades they described largely corresponded with the most widely accepted infrageneric grouping of the genus based on Bentham $(1848,1876)$. Clades 1 and 3 comprise all European, Asian, and African Salvia species and one small, morphologically distinct group of American species belonging to Clade 1 . Clade 1 is primarily native to Europe and includes members of subgenera Salvia, Leoinia, and Sclarea, whereas Clade 3 is largely East Asian and corresponds generally to section Drymospace. Clade 2 is comprised of species that are exclusively native to the Americas and is comprised of the subgenera Audibertia and Calosphace. Because the clades defined by Walker correspond largely with geographical distribution and with the subgenera and sections of Bentham, it is possible to extrapolate from the species included in Walker's study to classify most other Salvia species as probable members of one of the three clades. The wide divergence of these clades, especially Clades 1 and 2, lead to the hypothesis that crosses between the different clades will not be successful.

The chromosome numbers of Salvia species are unusual in their extreme variability. Published counts range from a low of $2 n=12$ in S. hispanica (Harley and Heywood, 1992) to a high of $2 n=88$ in the octoploid S. guaranitica (Alberto et al., 2003). In addition to wide variation in ploidy level in Salvia, the basic number of chromosomes is also wide-ranging with $x$ reported as $6,7,8,9,10,11$, and 15 for species within the genus (Goldblatt and Johnson, 1979; Harley and Heywood, 1992). Seven of 13 species studied by Alberto et al. (2003) had at least one known supernumerary chromosome (non-essential chromosomes absent in some individuals). It is possible that closely related species that appear to have different basic chromosome numbers might simply have supernumerary chromosomes that have not been properly identified as such.

To evaluate the potential of selected Salvia species as genetic sources for improvement of cultivated Salvia species and to provide information for plant breeders interested in 
developing hybrid Salvia, our objectives were to: 1) test the interspecific crossability of a select number of Salvia species from different clades and with different chromosome numbers; 2) establish chromosome numbers for selected Salvia species either lacking published counts or with inconsistently reported counts; and 3) evaluate inheritance of crop quality traits in the interspecific hybrid $S$. nemerosa $\times S$. transsylvanica.

\section{Materials and Methods}

Plant growth and pollination conditions. Nine Salvia species native to Europe and North and South America from Clades 1 and 2 of the genus (as defined by Walker et al., 2004) were chosen to incorporate a wide range of native climates, growth habits, chromosome numbers, and flower colors (Table 1). One genotype per species was used. Salvia transsylvanica, $S$. verticillata, $S$. azurea, and $S$. nemerosa 'Rosenwein' were grown from seed, and a single representative individual was selected and clonally propagated for crossing. All other species were obtained as vegetative propagules. All plants were grown in a greenhouse from Oct. 2007 through May 2009 under a 16-h photoperiod achieved with ambient daylight extended as needed with supplemental high-pressure sodium lighting (50 $\left.\mu \mathrm{mol} \cdot \mathrm{m}^{-2} \cdot \mathrm{s}^{-1}\right)$ at $20{ }^{\circ} \mathrm{C}$. All species in the study flowered under these conditions with the exception of S. madrensis. Salvia madrensis is a fall-flowering plant in the wild; therefore, plants were transferred to short-day conditions (a truncated 9-h photoperiod obtained by covering plants with opaque cloth from 1700 to $0800 \mathrm{HR}$ daily), which induced flowering in $S$. madrensis after 3 weeks (data not shown).

Species were crossed in a full diallel mating scheme. In all cases, except for $S$. nemorosa, the same genotype was used both as the pollen parent and seed parent for all crosses. Salvia nemorosa, however, is gynodioecious with a male sterility gene and an accompanying complex of lethality and sublethality factors (Linnert, 1958). Therefore, for crosses involving $S$. nemerosa, the male-sterile 'Caradonna' was used as the seed parent, and the male-fertile 'Rosenwein' was used as the pollen parent. For each interspecific cross combination, 100 flowers were pollinated. Pollinations were conducted from Oct. 2007 through Jan. 2008 and replicated from Oct. 2008 through Jan. 2009 with 50 pollinations of each cross combination each year.
The effects of year were not significant, so data from both replications were subsequently pooled. Seed parent flowers were emasculated the day before anthesis. Once the style had fully elongated, pollen was applied to the stigma directly from the dehiscing anther of the pollen parent. Pollinated flowers were observed for partial or complete seed development. Salvia floral morphology is such that the developing seeds are exposed to view, and any growth of the developing seed is easily observed. Crosses were rated unsuccessful if no seed development was observed, successful if mature, viable seed was produced, and considered abortive if seeds partially developed (as observed by an increase in size after pollination but abortion before maturity). To determine the level of self-fertility of the parent plants, 50 flowers of each species were self-pollinated as described for the crosspollinations ( 25 each year), although without emasculation. Salvia nemorosa was not self-pollinated as a result of male sterility as described previously and instead the cultivars Caradonna and Rosenwein were crossed. After pollination, seeds were observed and harvested as described for the interspecific crosses. All mature seed produced by successful crosses was harvested and sown under intermittent mist with bottom heat to observe germination.

HYBRID CONFIRMATION AND FERTILITY. The hybridity of the germinated seedlings was first observed based on intermediate phenotype and then confirmed using random amplified polymorphic DNA (RAPD) markers. DNA was isolated from leaf tissue of each putative hybrid using the DNeasy Plant Mini kit (Qiagen, Valencia, CA) following the manufacturer's protocol. Primer 3 (5'-agtcagccac-3') from an Operon RAPD 10mer primer kit A (Eurofins MWG Operon, Huntsville, AL) was used to amplify DNA for the $\mathrm{F}_{1} \mathrm{~s} S$. transsylvanica $\times S$. nemorosa, $S$. nemorosa $\times S$. transsylvanica, $S$. transsylvanica $\times S$. involucrata, $S$. guaranitica $\times S$. involucrata, and their parent species. Primer 5 (5'-aggggtcttg-3') from the same kit was used to amplify DNA from the $\mathrm{F}_{1} S$. greggii $\times S$. involucrata and its parent species. Polymerase chain reaction (PCR) conditions were as follows: initial denaturation at $94^{\circ} \mathrm{C}$ for $2 \mathrm{~min}$ followed by 40 cycles of $94^{\circ} \mathrm{C}$ for $2 \mathrm{~min}, 40^{\circ} \mathrm{C}$ for $2 \mathrm{~min}$, and $72^{\circ} \mathrm{C}$ for 2 min with a final elongation step at $72{ }^{\circ} \mathrm{C}$ for $10 \mathrm{~min}$. PCR products were separated on a $1 \%$ agarose gel containing ethidium bromide and visualized under ultraviolet light.

The fertility of the $F_{1}$ hybrids was measured by selfpollinating 50 flowers from each hybrid population. Hybrid

Table 1. Parental genotypes, native range, flower color, phylogenetic clade, and accession information for Salvia species used in a full diallel mating scheme.

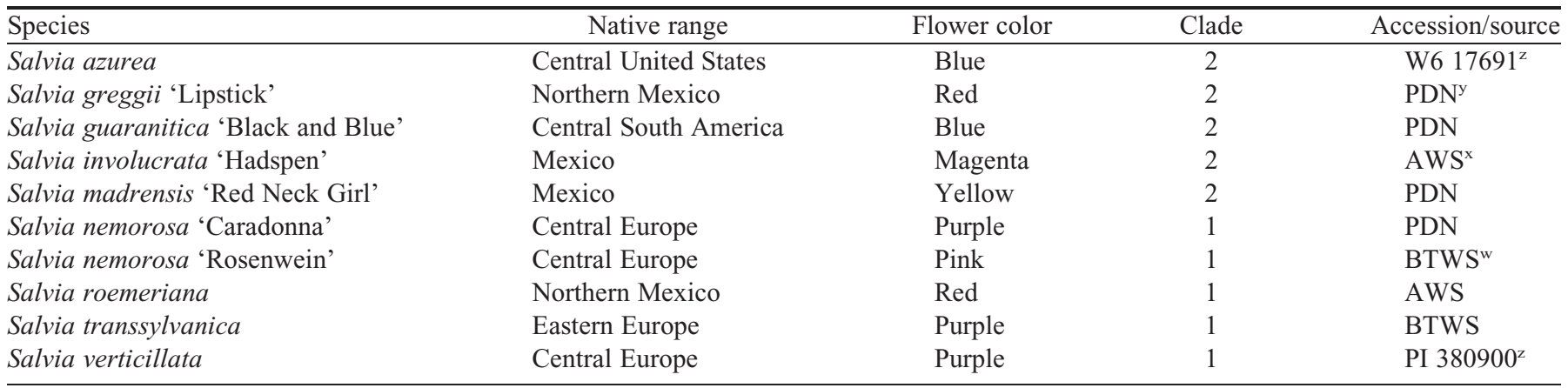

${ }^{\mathrm{z} U . S . ~ D e p a r t m e n t ~ o f ~ A g r i c u l t u r e ~ N a t i o n a l ~ P l a n t ~ G e r m p l a s m ~ S y s t e m ~ a c c e s s i o n ~ n u m b e r . ~}$

yPlant Delights Nursery, Raleigh, NC.

${ }^{x}$ A World of Salvias, Candor, NC.

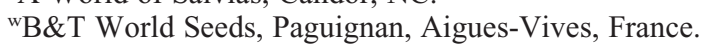


plants were also back-crossed to both of the parent species with 50 pollinations made for each reciprocal combination with each parent. Like with the original crosses, seed development was observed and any mature seed that developed was sown to observe germination.

Trait ANALYSIS AND INHERITANCE. Morphological traits were measured on the $\mathrm{F}_{1}$ hybrid plants and parents at the time of first flowering. Length and width of rosette leaves was measured, and height and length of individual flowers were measured. Measurements were made on six independent plants vegetatively propagated from a representative $F_{1}$ individual and the parental species. Inheritance of horticulturally important traits in the $S$. nemorosa $\times S$. transsylvanica hybrid was evaluated on a family of $124 \mathrm{~F}_{2}$ plants derived from a single representative $\mathrm{F}_{1}$ individual, parent species, and $\mathrm{F}_{1}$ plants. Total plant height, flower length, number of branches in the inflorescence, time to flower, leaf length, and number of leaves produced before flowering were measured at the time of first flowering.

Chromosome counts. Chromosome counts were performed on S. greggii, S. involucrata, S. madrensis, and S. transsylvanica because published chromosome counts were unavailable or published counts were inconsistent. In addition, chromosomes were counted for plants from all hybrid populations produced in this study. Chromosome counting protocols were adapted from Singh (2003). For all species and hybrids, counts were performed on root tips. For S. transsylvanica and S. transsylvanica $\times S$. involucrata, counts were also performed on anthers. To collect root tips, greenhouse-grown plants were removed from their pots, and exposed root tips were collected and placed directly into a pretreatment solution of $2 \mathrm{~mm}$ 8-hydroxyquinoline. For anther counts, flower buds between 0.75 and $1.5 \mathrm{~mm}$ long were removed from greenhouse-grown plants and placed directly in $2 \mathrm{~mm} 8$-hydroxyquinoline. Root tips and flower buds in the 8-hydroxyquinoline pretreatment solution were placed in $18{ }^{\circ} \mathrm{C}$ for 3 to $4 \mathrm{~h}$. Tissues were then transferred to $3: 1$ solution of $100 \%$ ethanol and glacial acetic acid for $24 \mathrm{~h}$ for fixation and then to $70 \%$ ethanol for storage. Tissues were stored in ethanol for 1 week before squashing. Root tips were then squashed in a drop of $2 \%$ acetocarmine stain and observed at $1000 \times$ magnification using phase contrast. The developing anthers were dissected out of the flower buds under a dissecting microscope at $10 \times$ magnification, then squashed and observed as described for the root tips. A minimum of five cells with clearly visible chromosomes was observed for each genotype.

Data analysis. Analyses of variance, means separation (determined by Fisher's least significant difference at $P=$ 0.05 ), and Pearson correlation coefficients were determined using SPSS (Version 17.0 for Windows; SPSS, Chicago, IL).

\section{Results}

Overall, crossability among the selected species was low with only five of 72 interspecific cross combinations producing viable seed. However, nearly half of the crosses produced some seeds showing partial development. The 37 cross combinations producing viable or partially developed seed are presented in Table 2. In most cases, only limited numbers of abortive seeds were produced, usually in $5 \%$ of pollinations or fewer, with the exception of $S$. nemorosa $\times S$. roemeriana in which nearly all seeds began to develop and aborted (data not shown). Only one species combination, $S$. nemorosa and $S$. transsylvanica, was
Table 2. Interspecific crosses and self-pollinations from a full diallel mating scheme that yielded complete or partial seed development. ${ }^{\mathrm{z}}$

\begin{tabular}{|c|c|c|}
\hline Cross & $\begin{array}{l}\text { Successful } \\
\text { crosses }(\%)\end{array}$ & $\begin{array}{c}\text { Avg seeds per } \\
\text { cross (no.) }\end{array}$ \\
\hline Salvia. azurea $\times$ self & 46 & 1.3 \\
\hline S. azurea $\times$ Salvia greggii & $\mathrm{pd}^{\mathrm{y}}$ & 0 \\
\hline S. azurea $\times$ Salvia guaranitica & $\mathrm{pd}$ & 0 \\
\hline S. azurea $\times$ Salvia madrensis & $\mathrm{pd}$ & 0 \\
\hline S. azurea $\times$ Salvia verticillata & $\mathrm{pd}$ & 0 \\
\hline$S$. greggii $\times$ self & 40 & 1.7 \\
\hline S. greggii $\times S$. guaranitica & $\mathrm{pd}$ & 0 \\
\hline S. greggii $\times$ Salvia involucrata & 34 & 1.5 \\
\hline S. greggii $\times S$. madrensis & $\mathrm{pd}$ & 0 \\
\hline S. greggii $\times$ Salvia roemeriana & pd & 0 \\
\hline S. guaranitica $\times$ self & 32 & 2.4 \\
\hline S. guaranitica $\times S$. involucrata & 1 & 1 \\
\hline S. guaranitica $\times S$. madrensis & $\mathrm{pd}$ & 0 \\
\hline S. guaranitica $\times S$. roemeriana & $\mathrm{pd}$ & 0 \\
\hline S. involucrata $\times S$. azurea & pd & 0 \\
\hline S. involucrata $\times S$. greggii & $\mathrm{pd}$ & 0 \\
\hline S. involucrata $\times S$. guaranitica & $\mathrm{pd}$ & 0 \\
\hline S. involucrata $\times$ self & 6 & 2.3 \\
\hline S. madrensis $\times S$. greggii & $\mathrm{pd}$ & 0 \\
\hline S. madrensis $\times S$. involucrata & $\mathrm{pd}$ & 0 \\
\hline S. madrensis $\times$ self & 28 & 1.4 \\
\hline$S$. madrensis $\times S$. roemeriana & $\mathrm{pd}$ & 0 \\
\hline S. madrensis $\times S$. verticillata & $\mathrm{pd}$ & 0 \\
\hline Salvia nemorosa $\times S$. nemorosa ${ }^{\mathrm{x}}$ & 90 & 1.7 \\
\hline S. nemorosa $\times S$. roemeriana & $\mathrm{pd}$ & 0 \\
\hline S. nemorosa $\times$ Salvia transslyvanica & 72 & 1.3 \\
\hline S. nemorosa $\times S$. verticillata & $\mathrm{pd}$ & 0 \\
\hline S. roemeriana $\times S$. azurea & pd & 0 \\
\hline S. roemeriana $\times S$. guaranitica & $\mathrm{pd}$ & 0 \\
\hline$S$. roemeriana $\times S$. involucrata & $\mathrm{pd}$ & 0 \\
\hline S. roemeriana $\times S$. nemorosa & $\mathrm{pd}$ & 0 \\
\hline S. roemeriana $\times$ self & 100 & 3.8 \\
\hline S. roemeriana $\times S$. transslyvanica & $\mathrm{pd}$ & 0 \\
\hline S. transslyvanica $\times S$. involucrata & 1 & 1 \\
\hline S. transslyvanica $\times S$. nemorosa & 1 & 1 \\
\hline S. transslyvanica $\times$ self & 100 & 2.6 \\
\hline S. verticillata $\times$ self & 18 & 1 \\
\hline
\end{tabular}

zPercentage of successful crosses between species is out of 100 pollinations, whereasa percentage of successful self-pollinations is out of 50 pollinations. Average seeds per cross is out of a maximum potential of four seeds.

${ }^{\mathrm{y}} \mathrm{pd}$ indicates crosses that showed partial development (an increase in size) but aborted before seed maturation.

'Salvia nemerosa 'Caradonna' $\times$ S. nemerosa 'Rosenwein'.

successful in both reciprocal crosses (Table 2). Success rate of this cross combination was dramatically lower with $S$. transsylvanica as the seed parent than as the pollen parent. For the other three successful hybrid combinations $(S$. transsylvanica $\times$ $S$. involucata, $S$. greggii $\times S$. involucrata, $S$. guaranitica $\times S$. involucrata), the reciprocal crosses produced no viable seed. Self-pollination of the parent species revealed significant variability in self-fertility. Although most species showed a high degree of fertility when self-pollinated, S. verticillata and $S$. involucrata had very low seed set (Table 2). For successful cross combinations, all of the $\mathrm{F}_{1}$ seeds germinated (data not shown). 
In all hybrids, at least one phenotypic trait varied significantly from the parent species (Table 3). In most cases, hybrid traits were intermediate between the two parents, although in the crosses $S$. transsylvanica $\times S$. involucrata and $S$. transsylvanica $\times S$. nemorosa, leaf length and width of the $F_{1}$ were significantly larger than either parent plant. Hybridity was confirmed based on RAPD banding pattern (Fig. 1).

Of all hybrids produced, $S$. nemorosa $\times S$. transsylvanica showed the highest fertility when used as the female parent and back-crossed to either parent species (Table 4). Salvia transsylvanica $\times S$. involucrata was highly fertile when self-pollinated but failed to back-cross with either parent species. The $S$. transsylvanica $\times S$. nemerosa hybrids exhibited low self-fertility but moderate fertility when back-crossed to either parent species. All harvested mature seeds for each cross combination germinated successfully (data not shown). The other two hybrids produced, $S$. greggii $\times S$. involucrata and $S$. guaranitica $\times S$. involucrata, were completely sterile when selfed or back-crossed to either parent and are therefore not included in Table 4 . The $\mathrm{F}_{1}$ hybrid plants had chromosome numbers as expected based on parental chromosome numbers with the exception of S. transsylvanica $\times$ S. involucrata (Table 5). With 38 chromosomes, this hybrid appears to be an allopolyploid, possibly formed from the combination of restitution gametes or spontaneous chromosome doubling of the zygote.

The $S$. nemorosa $\times S$. transsylvanica $\mathrm{F}_{2}$ population exhibited transgressive segregation for a wide range of phenotypic traits (Fig. 2). For example, time to flower varied from 13 to 29 weeks compared with 15 and 19 weeks to flower for $S$. nemerosa and S. transsylvanica, respectively. Similarly, plant height at flowering ranged from 20 to $85 \mathrm{~cm}$ for $\mathrm{F}_{2}$ individuals compared with 30 and $55 \mathrm{~cm}$ for $S$. nemerosa and $S$. transsylvanica, respectively. In contrast, only three of the $124 \mathrm{~F}_{2}$ individuals had flower lengths less than $S$. nemerosa or greater than $S$. transsylvanica (Fig. 2). Many of the measured traits were significantly correlated in the $\mathrm{F}_{2}$ population. Plant height was correlated positively with flower length, leaf length, inflorescence branch number, and time to flower. Time to flower was correlated positively with flower length (Table 6). Although many of these traits were significantly correlated, individuals with combinations of desirable trait values (e.g., large flowers with compact growth habit) were identified within the population (Fig. 3) showing the associations may be relatively weak.

\section{Discussion}

It is often assumed that crosses between organisms with equal chromosome numbers will be more successful, but

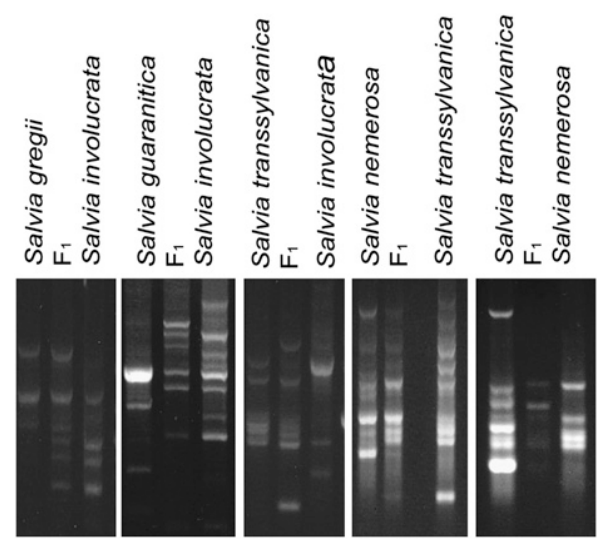

Fig. 1. Random amplified polymorphic DNA banding patterns for parental Salvia species and $\mathrm{F}_{1}$ hybrids.

notably in this study, three of the five successful crosses were between species with different basic chromosome numbers. Of those crosses, the hybrid between species with the same basic chromosome numbers $(S$. greggii $\times S$. involucrata, $S$. guaranitica $\times S$. involucrata) were sterile, whereas the crosses between individuals with different basic chromosome numbers $(S$. transsylvanica $\times S$. involucrata, $S$. transsylvanica $\times S$. nemorosa, $S$. nemorosa $\times S$. transsylvanica) were fertile, results opposite from what would be expected. In the case of $S$. transsylvanica $\times S$. involucrata, the fertility may be explained by the likely allopolyploid nature of this hybrid (based on chromosome counts for the parents and hybrid), but no such 
Table 4. Fertility of interspecific Salvia hybrids after self-pollination or back-crossing to parental species. $^{\text {z }}$

\begin{tabular}{|c|c|c|}
\hline Cross & $\begin{array}{l}\text { Successful } \\
\text { crosses }(\%)\end{array}$ & $\begin{array}{c}\text { Avg seeds } \\
\text { per cross (no.) }\end{array}$ \\
\hline$($ Salvia transsylvanica $\times$ Salvia involucrata $) \times$ self & 60 & 1.8 \\
\hline$(S$. transsylvanica $\times S$. involucrata $) \times S$. transsylvanica & 0 & 0 \\
\hline$(S$. transsylvanica $\times S$. involucrata $) \times S$. involucrata & 0 & 0 \\
\hline S. transsylvanica $\times(S$. transsylvanica $\times S$. involucrata $)$ & 0 & 0 \\
\hline S. involucrata $\times(S$. transsylvanica $\times S$. involucrata $)$ & 0 & 0 \\
\hline$($ Salvia nemorosa $\times$ S. transsylvanica $) \times$ self & 46 & 1.0 \\
\hline$(S$. nemorosa $\times S$. transsylvanica $) \times S$. nemorosa & 76 & 1.5 \\
\hline$(S$. nemorosa $\times S$. transsylvanica $) \times S$. transsylvanica & 64 & 1.7 \\
\hline S. nemorosa $\times(S$. nemorosa $\times S$. transsylvanica $)$ & 40 & 1.2 \\
\hline S. transsylvanica $\times(S$. nemorosa $\times S$. transsylvanica $)$ & 20 & 1.2 \\
\hline$(S$. transsylvanica $\times S$. nemorosa $) \times$ self & 8 & 1.0 \\
\hline$(S$. transsylvanica $\times S$. nemorosa $) \times S$. transsylvanica & 24 & 1.0 \\
\hline$(S$. transsylvanica $\times S$. nemorosa $) \times S$. nemorosa & 44 & 1.0 \\
\hline S. transsylvanica $\times(S$. transsylvanica $\times S$. nemorosa $)$ & 52 & 2.0 \\
\hline S. nemorosa $\times($ S. transsylvanica $\times S$. nemorosa $)$ & 48 & 1.3 \\
\hline
\end{tabular}

${ }^{\mathrm{z}}$ Successful cross percentages are out of 50 total pollinations for each cross. Average seeds per cross is out a maximum potential of four seeds.

Table 5. Chromosome numbers of Salvia species and interspecific hybrids.

\begin{tabular}{|c|c|c|}
\hline Species & $2 n=$ & Reference: \\
\hline Salvia azurea & 20 & $\begin{array}{l}\text { Harley and Heywood, } \\
1992\end{array}$ \\
\hline Salvia guaranitica & 88 & Alberto et al., 2003 \\
\hline Salvia greggii & $23^{z}$ & This study \\
\hline Salvia involucrata & 22 & This study \\
\hline Salvia madrensis & 20 & This study \\
\hline Salvia nemorosa & 14 & $\begin{array}{l}\text { Goldblatt and Johnson, } \\
1979\end{array}$ \\
\hline Salvia roemeriana & 28 & $\begin{array}{l}\text { Walker and Elisens, } \\
2001\end{array}$ \\
\hline Salvia transsylvanica & 16 & This study \\
\hline Salvia verticillata & 16 & $\begin{array}{l}\text { Goldblatt and Johnson, } \\
1979\end{array}$ \\
\hline \multicolumn{3}{|l|}{$\mathrm{F}_{1}$ hybrids } \\
\hline S. greggii $\times S$. involucrata & $23^{z}$ & This study \\
\hline S. nemorosa $\times S$. transsylvanica & 15 & This study \\
\hline S. transsylvanica $\times S$. nemorosa & 15 & This study \\
\hline S. guaranitica $\times S$. involucrata & 55 & This study \\
\hline S. transsylvanica $\times S$. involucrata & 38 & This study \\
\hline
\end{tabular}

${ }^{\mathrm{z}}$ Likely $2 \mathrm{n}=22+1$ supernumerary chromosome.

explanation is possible with the $S$. transsylvanica $\times S$. nemorosa and $S$. nemorosa $\times S$. transsylvanica hybrids.

Hybrids between Salvia species with unequal chromosome numbers have been reported in the past. Salvia nemorosa, with 14 chromosomes, has been reported to form natural, fertile hybrids with S. pratensis (Kerner con Marilaun, 1891) with 18 chromosomes (Goldblatt and Johnson, 1979). Epling (1938) observed natural hybrids between $S$. columbaria $(2 n=26)$ and S. mellifera $(2 n=30)$ (Epling et al., 1962). Salvia farinacea $[2 n=18$ (Haque and Ghoshal, 1980) or $2 n=20$ (Alberto et al., 2003)] and S. longispicata $(2 n=22$; Goldblatt and Johnson, 1979) have formed a chance sterile hybrid in cultivation (Clebsch, 2003). Together, these data suggest that Salvia is highly tolerant of aneuploidy in its hybrids and that different chromosome numbers in this genus are not an absolute barrier to hybrid formation.

There are other genera in which species show a high level of crossability between different basic chromosome numbers. In Brassica, $B$. nigra $(2 n=16), B$. oleracea $(2 n=$ $18)$, and $B$. campestris $(2 n=20)$ have all hybridized naturally to form the allotetraploid species $B$. carinata $(2 n=34) B$. juncea $(2 n=$ $36)$, and B. napus $(2 n=38)$ and can be hybridized artificially producing $\mathrm{F}_{1}$ plants that have low fertility but are not completely sterile (U, 1935). Such successful hybridization between different chromosome numbers is the exception rather than the rule, however. Ladizinsky (1992) reviewed efforts to produce interspecific hybrids in 11 genera of important crop plants. Comparing Ladizinsky's crossability data with chromosome numbers compiled by Goldblatt and Johnson (1979) reveals that although a few hybrids were between species of different ploidy, none were between species with different basic chromosome numbers.

The most unexpected result of the crossability study was the production of a successful hybrid between $S$. transsylvanica and $S$. involucrata. These species have been placed in different
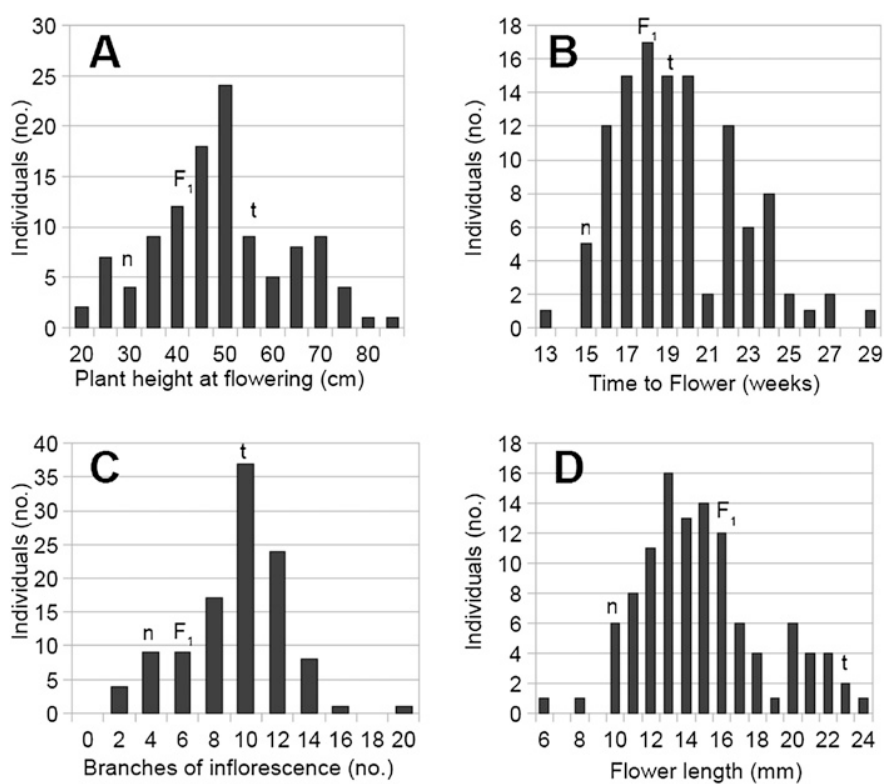

Fig. 2. Population distributions of (A) plant height at first flower, (B) time to flower, (C) branch number of inflorescence, and (D) flower length in the Salvia nemorosa $\times$ Salvia transsylvanica $\mathrm{F}_{2}$ population; $\mathrm{n}, \mathrm{t}$, and $\mathrm{F}_{1}$ indicate values for $S$. nemorosa, $S$. transsylvanica, and their $\mathrm{F}_{1}$ hybrid, respectively. 
Table 6. Pearson's correlation coefficients of selected phenotypic traits in a Salvia nemorosa $\times$ Salvia transsylvanica $\mathrm{F}_{2}$ population.

\begin{tabular}{lccccc}
\hline & $\begin{array}{c}\text { Time to } \\
\text { flower }\end{array}$ & Plant ht & $\begin{array}{c}\text { Branch } \\
\text { no. }\end{array}$ & Leaf no. & $\begin{array}{c}\text { Leaf } \\
\text { length }\end{array}$ \\
\hline Flower length & $0.23^{*}$ & $0.25^{* *}$ & -0.02 & 0.14 & $0.53^{* *}$ \\
Time to flower & & $0.20^{*}$ & -0.17 & $0.88^{* * *}$ & -0.02 \\
Plant ht & & & $0.24^{*}$ & 0.16 & $0.43^{* * *}$ \\
Branch no. & & & & -0.15 & $0.23^{*}$ \\
Leaf no. & & & & & $-0.21^{*}$ \\
\hline
\end{tabular}

*, **, *** denote significance at $P<0.05,0.01$, and 0.001 , respectively.

clades of the genus, which are thought to be widely divergent. However, the conclusions of a recent phylogenetic study indicate that these two clades are only classified as members of the same genus as a result of chance convergent evolution of the key morphological traits used to define the genus Salvia (Walker et al., 2004). This successful hybrid between the two species indicates that the two clades may be more closely related than is indicated by Walker's phylogeny of the genus.

Most interspecific hybridization efforts start with the assumption that closely related species with the same chromosome number will be the most likely to successfully hybridize. Our data conflict with those assumptions, indicating that in Salvia, chromosome number is not an accurate predictor of interspecific hybrid formation potential and that hybrids are possible between extremely divergent parts of this genus.
Furthermore, our data likely underestimate the potential for successful interspecific hybridization among Salvia species. It is possible that many of the crosses that failed to produce seed in this study would be successful with other genotypes or in other conditions. These data, unfortunately, do not indicate any systematic method to predict interspecific hybridity potential within the genus, meaning breeders will have to explore possible hybrids largely through trial and error.

Analysis of the $S$. nemorosa $\times S$. transsylvanica $\mathrm{F}_{2}$ family revealed a strong potential to integrate valuable traits from the wild species for improvement of S. nemorosa (Fig. 2), a popular herbaceous perennial plant. The $\mathrm{F}_{2}$ family exhibited significant transgressive segregation for numerous traits, likely as a result of heterozygosity of the parent plants, including many individuals with significantly larger flowers than $S$. nemorosa and a more profuse floral display resulting from greater branching of the inflorescence. Unfortunately, flower size was correlated positively with plant height and time to flower (Table 6), and inflorescence number was correlated positively with plant height. Excessive plant height and delayed flowering are undesirable traits for ornamental crops. However, these correlations were relatively weak and highly ornamental individuals combining the desirable growth habit of $S$. nemorosa with the improved floral characteristics of $S$. transsylvanica existed in this population (Fig. 3). Because most herbaceous perennial Salvia are asexually propagated, improved Salvia cultivars lacking the negative traits of the wild species can be selected directly from this hybrid population.
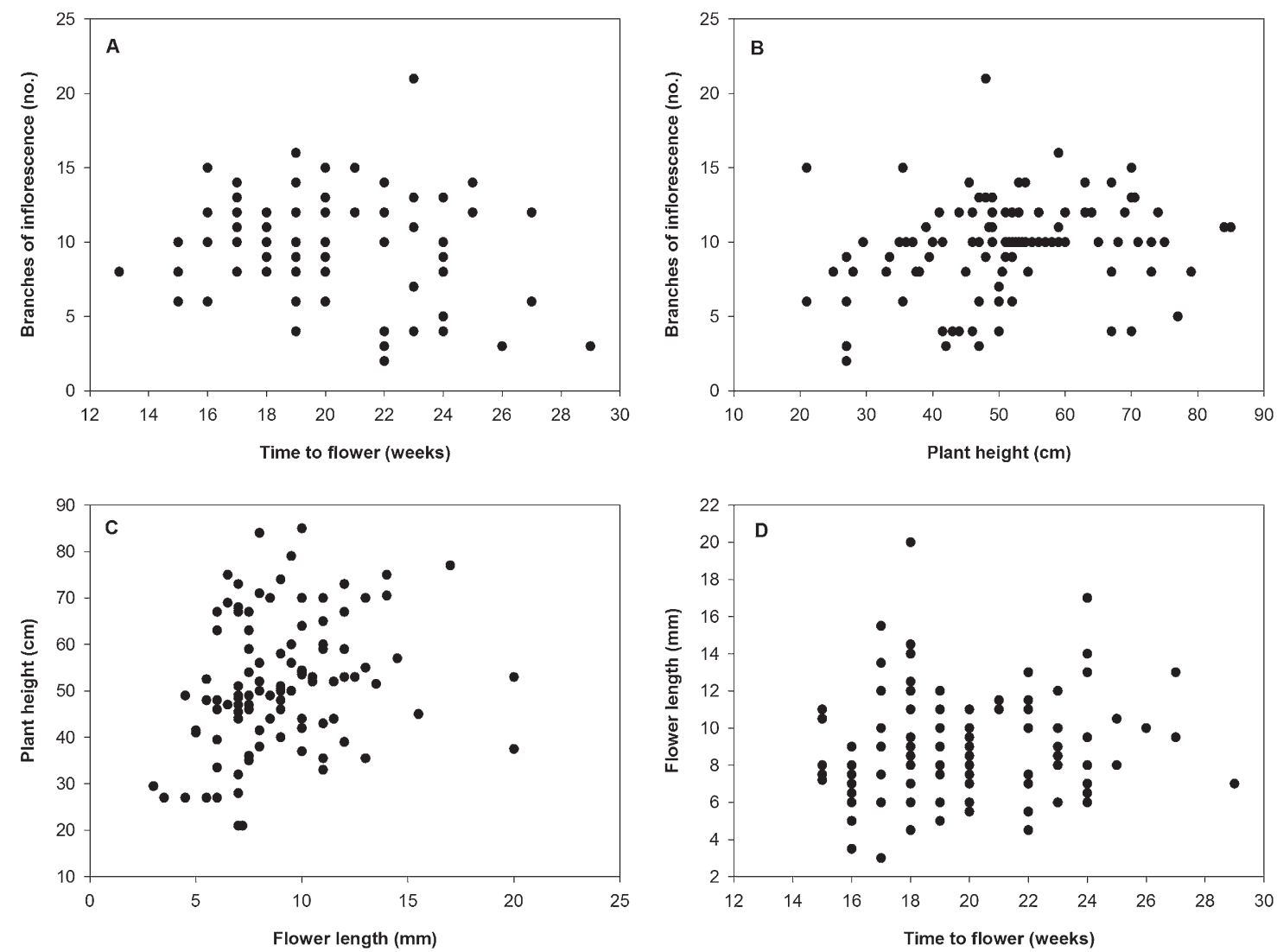

Fig. 3. Population distributions for morphological traits and time to flower for Salvia nemorosa $\times$ Salvia transsylvanica $\mathrm{F}_{2}$ generation individuals: $(\mathbf{A})$ inflorescence branch number versus time to flower, (B) inflorescence branch number versus plant height, $(\mathbf{C})$ plant height versus flower length, and (D) flower length versus time to flower. 
In conclusion, crossability among the selected Salvia species was low. However, almost half of the cross combinations produced partially developed seeds. Embryo rescue techniques may be successful for recovering hybrid plants of these cross combinations. Salivia transsylvanica may be a useful genetic source for improving floral size of the popular herbaceous perennial $S$. nemerosa.

\section{Literature Cited}

Alberto, C.M., A.M. Sanso, and C.C. Xifreda. 2003. Chromosomal studies in species of Salvia (Lamiaceae) from Argentina. Bot. J. Linn. Soc. 141:483-490.

Bentham, G. 1848. Labiatae, p. 27-603. In: De Candolle, A. (ed.). Prodomus systematis naturalis regni vegetabilis, Vol. 12. Treuttel et Wortz, Paris, France.

Bentham, G. 1876. Labiatae, p. 1160-1196. In: Bentham, G. and J. D. Hooker (eds.). Genera plantarum. Vol. 2. Reeve, London, UK.

Claßen-Bockhoff, R., P. Wester, and E. Tweraser. 2003. The staminal lever arm mechanism in Salvia-A review. Plant Biol. 5:33-41.

Clebsch, B. 2003. The new book of salvias. Timber Press, Portland, OR. Epling, C. 1938. The California salvia. Ann. Mo. Bot. Gard. 25:95-188. Epling, C., H. Lewis, and P. Raven. 1962. Chromosomes of Salvia: Section audibertia. Aliso 5:217-221.

Goldblatt, P. and D.E. Johnson (eds.). 1979. Index to plant chromosome numbers. Missouri Bot. Garden, St. Louis, MO.

Haque, M.S. and K.K. Ghoshal. 1980. Karyotypes and chromosome morphology in the genus Salvia Linn. Cytologia (Tokyo) 45:627-640.

Harlan, J.R. and J.M.J. DeWet. 1971. Toward a rational classification of cultivated plants. Taxon 20:509-517.

Harley, R.M. and C.A. Heywood. 1992. Chromosome numbers in tropical American Labiatae, p. 211-246. In: Harley, R.M. and
T. Reynolds (eds.). Advances in labiate science. Royal Botanic Gardens, Kew, UK.

Kerner con Marilaun, A. 1891. Pflanzenleben. Bd. 2. Geschichte der Pflazen Bibliographisches Institut, Leipzig, Germany/Vienna, Austria.

Ladizinsky, G. 1992. Crossability relations, p. 15-31 In: Kalloo, G. and J.B. Chowdhury (eds.). Distant hybridization of crop plants. Springer-Verlag, Berlin, Germany.

Linnert, G. 1958. Kerngesteuerte Gynodiozie bei Salvia nemorosa. Mol. Gen. Genet. 89:36-51.

Mabberly, D.J. 2008. Mabberly's plant book. 3rd Ed. Cambridge University Press, Cambridge, UK.

Putievsky, E., U. Ravid, N. Diwan-Rinzler, and D. Zohary. 1990. Genetic affinities and essential oil composition of Salvia officinalis L., S. fruticosa Mill., S. tomentosa and their hybrids. Flavour Fragrance J. 5:121-123.

Sanchez-Gomez, P., M.C. Soriano-Cano, J.A. Sotomayor-Sanchez, and M.C. Garcia-Vallejo. 1995. Essential oils of new hybrid: Salvia officinalis $\times$ S. lavandulifolia ssp. vellera. J. Essential Oil Res. 7:317318.

Singh, R.J. 2003. Plant cytogenetics. 2nd Ed. CRC Press, Boca Raton, FL.

Sybenga, J. 1992. Cytogenetics in plant breeding. Springer-Verlag, Berlin, Germany.

U, N. 1935. Genome analysis in Brassica with special reference to the experimental formation of B. napus and its peculiar mode of fertilization. Jpn. J. Bot. 7:389-452.

Walker, J.B. and W.J. Elisens. 2001. A revision of Salvia section Heterosphace in western North America. Sida 19:571-589.

Walker, J.B., K.J. Sytsma, J. Treutlein, and M. Wink. 2004. Salvia is not monophyletic: Implications for the systematics, radiation, and ecological specializations of Salvia and the tribe Mentheae. Amer. J. Bot. 91:1115-1125. 